\title{
MOLECULAR TYPING, PATHOGENICITY FACTOR GENES AND ANTIMICROBIAL SUSCEPTIBILITY OF VANCOMYCIN RESISTANT ENTEROCOCCI IN BELGRADE, SERBIA
}

\author{
MiLiCA JOVANOVIĆ ${ }^{*}$, BRANKO MiLOŠEVIĆ 2,3 , TANJA TOŠIĆ ${ }^{1}$, \\ Goran SteVanović ${ }^{2,3}$, Vesna MiOlJEVić ${ }^{4}$, NikOla InĐiĆ 5 , \\ BRANKO VELEBIT ${ }^{6}$ and MARCUS ZERVOS ${ }^{7,8}$
}

${ }^{1}$ Department of Microbiology of Clinical Center of Serbia, Belgrade, Serbia

${ }^{2}$ Clinic for Infectious and Tropical Diseases of Clinical Center of Serbia, Belgrade, Serbia

${ }^{3}$ University of Belgrade, School of Medicine, Belgrade, Serbia

${ }^{4}$ Department of Hospital Epidemiology of Clinical Center of Serbia, Belgrade, Serbia

${ }^{5}$ Center for Preventive Medical Care Belgrade, Belgrade, Serbia

${ }^{6}$ Institute of Meat Hygiene and Technology, Belgrade, Serbia

${ }^{7}$ Henry Ford Hospital, Detroit, Michigan, USA

${ }^{8}$ Wayne State University School of Medicine, Detroit, Michigan, USA

(Received: 17 November 2014; accepted: 10 February 2015)

In this study the distribution of species and antimicrobial resistance among vancomycin resistant enterococci (VRE) recovered from clinical specimens obtained from five hospitals in Belgrade was analyzed. Strains were further characterized by pulsed-field gel electrophoresis (PFGE). Polymerase chain reaction (PCR) was used to investigate the presence of $\operatorname{van} A$ and $\operatorname{van} B$ genes and pathogenicity factor genes. Identification of $194 \mathrm{VRE}$ isolates revealed 154 Enterococcus faecium, 21 Enterococcus faecalis, 10 Enterococcus raffinosus and 9 Enterococcus gallinarum. This study revealed existence of 8 major clones of VRE. PCR determined vanA gene to be present in all of the VRE studied. Esp and $h y l$ genes were present in $29.22 \%$ and $27.92 \%$ of $E$. faecium, respectively, and in $76.19 \%$ and 0 of E. faecalis, respectively. Esp and hyl genes were not found more frequently in members of predominant clones of E. faecium than in single isolates; nor was their presence connected to invasiveness.

Keywords: vancomycin resistant enterococci (VRE), pulsed-field gel electrophoresis (PFGE), pathogenicity factor genes, antimicrobial resistance

* Corresponding author; E-mail: mijovan@eunet.rs 


\section{Introduction}

Enterococci are natural inhabitants of the gastrointestinal tract of humans and other animals. Causative agents of invasive and non-invasive infections and harmless commensals of the digestive and urogenital tracts of humans and mammals became more dangerous and difficult to treat when they gained another feature: vancomycin resistance genes. With the emergence of vancomycin resistance, treatment options for infections caused by this microorganism became narrower.

Until recently, Enterococcus faecalis has been reported to be responsible for 80 to $90 \%$ of all clinical isolates, while Enterococcus faecium accounted for 5 to 15\%. Other Enterococcus species (Enterococcus gallinarum, Enterococcus casseliflavus, Enterococcus durans, Enterococcus avium, and Enterococcus raffinosus) are encountered much less frequently and account for less than 5\% of clinical isolates [1].

Seven phenotypes of acquired vancomycin resistance have been reported in enterococci [2]; the most prevalent are VanA and VanB, in which the genes encoding resistance are associated with mobile genetic elements that allow resistance to spread clonally and laterally [3]. Acquired resistance to glycopeptides (vanA and van B) has been reported for E. faecalis, E. faecium, E. avium, E. durans, E. raffinosus, E. gallinarum, E. casseliflavus, Enterococcus hirae and Enterococcus mundtii [4].

In this study, we analyzed the distribution of species and antimicrobial resistance among enterococci recovered from clinical specimens obtained from five hospitals in Belgrade over a five-year period. Clonal relatedness and presence of pathogenicity factor genes, especially in invasive isolates of VRE, were also determined.

\section{Materials and Methods}

\section{Bacterial isolates}

A prospective study was conducted from January 2002 to October 2006 in the Bacteriology laboratory of the Clinic for Infectious and Tropical Diseases. The Clinic is part of the Clinical Center of Serbia (CCS), the biggest tertiary care institution in the country, with 3300 beds and a full range of medical specialties. The Bacteriology Laboratory of the Clinic for Infectious and Tropical Diseases process specimens predominantly for that Clinic, but also for other clinics of the CCS. In addition to those obtained from the CCS, the study included VRE strains 
Table I. Distribution of Enterococcus spp. isolated from hospitalized patients, according to clinics and hospitals

\begin{tabular}{|c|c|c|c|c|c|}
\hline Hospitals & E. faecium & E. faecalis & E. raffinosus & E. gallinarum & Total \\
\hline \multicolumn{6}{|l|}{ Clinical Center of Serbia } \\
\hline \multicolumn{6}{|l|}{$\begin{array}{l}\text { Clinic for Infectious } \\
\text { and Tropical }\end{array}$} \\
\hline Diseases & 34 & 2 & 2 & & 38 \\
\hline Clinic for Hematology & 65 & 3 & & & 68 \\
\hline ICU of Emergency Center & 24 & 12 & 7 & 8 & 51 \\
\hline $\begin{array}{l}\text { Clinic for Pulmonary Diseases } \\
\text { and Tuberculosis }\end{array}$ & 11 & 1 & & 1 & 13 \\
\hline Clinic for Neurology & 1 & & & & 1 \\
\hline Gynecology-Obstetrics Clinic & & & 1 & & 1 \\
\hline $\begin{array}{l}\text { Clinic for Cardio-Vascular } \\
\text { Diseases }\end{array}$ & & 3 & & & 3 \\
\hline Neuro-Surgical Clinic & 3 & & & & 3 \\
\hline $\begin{array}{l}\text { Clinic for Ortopaedic } \\
\text { and Traumatology }\end{array}$ & 1 & & & & 1 \\
\hline Clinical Hospital Center Dedinje & 8 & & & & 8 \\
\hline Dragiša Mišović Hospital & 4 & & & & 4 \\
\hline Childrens' University Clinic & 2 & & & & 2 \\
\hline Oncology Institute & 1 & & & & 1 \\
\hline
\end{tabular}

provided by employees at four other health institutions. All four institutions are located in Belgrade (Table I).

Based on source of isolation, three categories of isolates were identified: invasive, 57 (29.38\%) from blood; non-invasive, 31 (15.98\%) from wounds and urine; and carrier, 106 (54.64\%) from stool, sputum, vagina, skin, nose and pharyngeal swabs.

\section{Preliminary identification}

Cultures were obtained within 24 hours of collection, placed on blood agar plates with $5 \%$ sheep blood, and incubated overnight at $35^{\circ} \mathrm{C}$. Isolates were identified at the genus level by the bile-esculin agar test accompanied by the Gram-staining method and catalase test. Beginning 1 January 2005, all entero- 
coccal isolates, irrespective of their clinical relevance, were screened for vancomycin resistance on Vancomycin screen agar (with $6 \mu \mathrm{g} / \mathrm{ml}$ of vancomycin). Before experimental testing, isolates were stored at $-70{ }^{\circ} \mathrm{C}$ in a brain heart infusion broth with $15 \%$ glycerol and cultured twice on Columbia agar supplemented with $5 \%$ sheep blood for 16 hours at $35^{\circ} \mathrm{C}$ in an oxygen atmosphere.

Phenotypic identification of Enterococcus species

Species identification was determined based on tests of carbohydrate fermentation, arginine hydrolysis, motility, yellow pigment production, hydrolysis of L-pyrrolidonyl- $\beta$-naphthylamide (PYR test), growth at $42{ }^{\circ} \mathrm{C}$ and tolerance to $6.5 \% \mathrm{NaCl}[5]$.

\section{Antimicrobial susceptibilities}

Antimicrobial susceptibilities were determined by the agar dilution method according to CLSI recommendations [6] for vancomycin, tetracycline, ciprofloxacin, linezolid, ampicillin, penicillin, chloramphenicol, nitrofurantoin, erythromycin, gentamicin, and streptomycin. E. faecalis ATCC 29212 was used as the reference strain. Isolates which were non-susceptible to three or more antimicrobials of different chemical groups were assessed as multidrug-resistant (MDR).

\section{PFGE typing}

Genomic DNA was prepared in agarose plugs using a previously described method [7], and digested with SmaI (New England Biolabs, Beverly, MA, USA). Pulsed-field gel electrophoresis was performed for 19 hours using a CHEF-DRIII (Bio-Rad, Hercules, CA, USA). SmaI-digested Staphylococcus aureus NCTC 8325 was molecular mass standard on all PFGE gels. SmaI restriction patterns were compared visually. Strains with identical PFGE patterns were deemed as parts of the clone and were considered to be the same type. Fragment patterns differing by one to six band differences, thus indicating closely or possibly related isolates [8], were considered subtype. To investigate the relatedness of the representative strains belonging to five major clones, a dendrogram of each of them was constructed using appropriate software (Bionumerics, version 2.5, Applied Maths, Kortrijik, Belgium). 
Detection of genes encoding for glycopeptide resistance

PCR experiments for detection of vancomycin resistance determinants for $v a n A$ and $v a n B$ genes were performed on all pulsotypes, according to the method of Dutka-Malen [9].

Detection of genes encoding pathogenicity factors

PCR experiments for detection of esp, cyl A, cyl B, efaAFs, efaAFm, cpd and $c o b$ genes were performed on all pulsotypes, using the method of Eaton and Gasson [10]. Multiplex PCR for asal, gel E, hyl genes was performed using a previously published method [11].

\section{Statistical analysis}

The Chi-square test was used to determine if pathogenicity factor genes were more common in invasive or carrier members of major clones or if the genes could be found more frequently in clonally related than unique strains. A $p$ value of $<0.05$ was considered statistically significant (Epi Info 3.5.1 software package).

\section{Results}

Antimicrobial susceptibility testing and detection of vancomycin resistance genes

A total of 194 VRE were consecutively recovered during the study period. In 2002 and 2003 one isolate per year was documented ( $0.51 \%)$, followed by 6 (3.10\%) in 2004, $140(72.17 \%)$ in 2005 and $46(23.71 \%)$ in 2006 up until October. The collection consisted of 154 (79.38\%) E. faecium, 21 (10.82\%) E. faecalis, 10 $(5.16 \%)$ E. raffinosus and 9 (4.64\%) E. gallinarum. Numbers of isolates per institution are displayed in Table I.

All of the investigated strains were MDR. All of them uniformly harboured vanA gene, demonstrated by PCR, irrespective of which species was tested. According to this finding, a high level of vancomycin resistance $(\geq 128 \mu \mathrm{g} / \mathrm{ml})$ was detected in all of them except for a part of E. faecalis clone c ( $9 / 12$ strains) (Table II). 
Table II. Antimicrobial susceptibilities (in $\mu \mathrm{g} / \mathrm{ml}$ ) of the isolates studied

\begin{tabular}{|c|c|c|c|c|c|c|c|c|c|c|c|c|c|c|c|c|c|}
\hline \multirow{2}{*}{ Antibio. } & \multirow{2}{*}{ Microorg. } & \multicolumn{16}{|c|}{ Antibiotic concentration $(\mu \mathrm{g} / \mathrm{ml})$} \\
\hline & & 0.25 & 0.5 & 1 & 2 & 4 & 8 & 16 & 32 & 64 & 128 & 256 & 512 & $<512$ & $>512$ & $<1024$ & $>1024$ \\
\hline \multirow[t]{4}{*}{ Van } & E. faecium & & & & & & & & & & 12 & 64 & 78 & & & & \\
\hline & E. faecalis & & & & & & & 1 & 3 & 5 & 2 & 8 & 2 & & & & \\
\hline & E. raffinosus & & & & & & & & & & & 6 & 4 & & & & \\
\hline & E. gallinarum & & & & & & & & & & & 3 & 6 & & & & \\
\hline \multirow[t]{4}{*}{ Tet } & E. faecium & 49 & 12 & 1 & 9 & 1 & 2 & 12 & 46 & 16 & 1 & 4 & 1 & & & & \\
\hline & E. faecalis & & & & & & & 1 & 7 & 13 & & & & & & & \\
\hline & E. raffinosus & & & & & & & & 1 & 3 & 6 & & & & & & \\
\hline & E. gallinarum & & & & & & & & & 7 & 2 & & & & & & \\
\hline \multirow[t]{4}{*}{ Cip } & E. faecium & & & & & & & 1 & 2 & 0 & 3 & 17 & 131 & & & & \\
\hline & E. faecalis & & & & & & & & & 14 & 6 & 1 & & & & & \\
\hline & E. raffinosus & & & & 4 & 5 & 1 & & & & & & & & & & \\
\hline & E. gallinarum & 1 & 0 & 4 & 1 & 1 & & & & & & 1 & 1 & & & & \\
\hline \multirow[t]{4}{*}{ Lzd } & E. faecium & & 1 & 25 & 128 & & & & & & & & & & & & \\
\hline & E. faecalis & & & 9 & 12 & & & & & & & & & & & & \\
\hline & E. raffinosus & & & 9 & 1 & & & & & & & & & & & & \\
\hline & E. gallinarum & & & 5 & 4 & & & & & & & & & & & & \\
\hline \multirow[t]{4}{*}{ Pen } & E. faecium & & & & & & & & & 1 & 57 & 41 & 55 & & & & \\
\hline & E. faecalis & & & & 1 & 2 & 10 & 8 & & & & & & & & & \\
\hline & E. raffinosus & & & & & & & 5 & 0 & 5 & & & & & & & \\
\hline & E. gallinarum & & & & & & 1 & 3 & 2 & 3 & & & & & & & \\
\hline \multirow[t]{4}{*}{ Amp } & E. faecium & & & & & & & & 6 & 6 & 87 & 36 & 19 & & & & \\
\hline & E. faecalis & & & 1 & 8 & 5 & 7 & & & & & & & & & & \\
\hline & E. raffinosus & & & & & & & 4 & 6 & & & & & & & & \\
\hline & E. gallinarum & & & & 1 & 3 & 3 & 2 & & & & & & & & & \\
\hline \multirow[t]{4}{*}{$\mathrm{Chl}$} & E. faecium & & & & 2 & 76 & 44 & 31 & 0 & 1 & & & & & & & \\
\hline & E. faecalis & & & & & 4 & 13 & 0 & 1 & 3 & & & & & & & \\
\hline & E. raffinosus & & & & & & & & & 7 & 3 & & & & & & \\
\hline & E. gallinarum & & & & & 3 & 4 & 0 & 0 & 2 & & & & & & & \\
\hline \multirow[t]{4}{*}{ Nit } & E. faecium & & & & & 7 & 6 & 43 & 80 & 18 & & & & & & & \\
\hline & E. faecalis & & & & 1 & 7 & 10 & 1 & 2 & & & & & & & & \\
\hline & E. raffinosus & & & & & & 1 & 9 & & & & & & & & & \\
\hline & E. gallinarum & & & & & & 7 & 1 & 1 & & & & & & & & \\
\hline \multirow[t]{4}{*}{ Ery } & E. faecium & & & & & & & & & & & & & 21 & 133 & & \\
\hline & E. faecalis & & & & & & & & & & & & & 10 & 11 & & \\
\hline & E. raffinosus & & & & & & & & & & & & & & 10 & & \\
\hline & E. gallinarum & & & & & & & & & & & & & & 9 & & \\
\hline \multirow[t]{4}{*}{ Gen } & E. faecium & & & & & & & & & & & & & 31 & 123 & & \\
\hline & E. faecalis & & & & & & & & & & & & & & 21 & & \\
\hline & E. raffinosus & & & & & & & & & & & & & & 10 & & \\
\hline & E. gallinarum & & & & & & & & & & & & & & 9 & & \\
\hline \multirow[t]{4}{*}{ Str } & E. faecium & & & & & & & & & & & & & & & 6 & 148 \\
\hline & E. faecalis & & & & & & & & & & & & & & & 1 & 20 \\
\hline & E. raffinosus & & & & & & & & & & & & & & & & 10 \\
\hline & E. gallinarum & & & & & & & & & & & & & & & 1 & 8 \\
\hline
\end{tabular}

Antibio. $=$ antibiotic, Microorg. $=$ microorganism, Van $=$ vancomycin, Tet $=$ tetracycline, Cip $=$ ciprofloxacin, Lzd $=$ linezolid, Pen $=$ penicillin, Amp = ampicillin, $\mathrm{Chl}=$ chloramphenicol, Nit = nitrofurantoin, Ery $=$ erythromycin, Gen $=$ gentamicin, $\mathrm{Str}=$ streptomycin 
The results of antimicrobial susceptibility testing reveal the best efficacy of linezolid (100\%), nitrofurantoin (90.7\%) and chloramphenicol (75.3\%). Sensitivity rates to high doses of aminoglycosides were $16 \%$ and $4.1 \%$ for gentamicin and streptomycin, respectively. Sensitivity rates to high doses of gentamicin were 20.1\% for E. faecium and 0 for E. faecalis.

The overall sensitivity for penicillin and ampicillin was $7.2 \%$ and $14.4 \%$, respectively. All E. faecalis retained sensitivity to ampicillin, a characteristic shared by E. gallinarum.

\section{PFGE}

The analysis of PFGE patterns revealed 49 different PFGE types and 12 subtypes among all of the study isolates of E. faecium. Of these, 5 PFGE types (clones) contained at least 14 of the isolates each; 7 types contained 2 to 7 isolates each, and 35 types were encountered only once. The 5 major clones of this enterococcus species contained 97 out of 154 E. faecium in total (Fig. 1).

Among E. faecalis 12 members $(57.1 \%$ of all E. faecalis) were typed as clone $\mathrm{c}$ while three other clones contained two or three members. Two isolates were unique and one clone contained two subtypes. Typing revealed only one clone in E. gallinarum (marked as G, with one subtype), as well as in E. raffinosus (grouped as R, with 5 subtypes). Characteristics of 8 major epidemic clones, comprising four species of enterococci discovered in this study, are presented in Table III.

\section{PCR: Pathogenicity factor genes}

Esp and hyl genes were detected in 45 isolates (29.2\%) and 43 isolates (27.9\%) of the E. faecium, respectively, and in 16 isolates $(76.2 \%)$ and $0(0 \%)$ of E. faecalis, respectively. Both genes were confirmed in 8 isolates $(5.2 \%)$ of E. faecium (Table IV).

Within five major clones of $E$. faecium (comprising 97 isolates), the esp or hyl gene was present in 38 strains (clones 20 and 24; 9/38 were invasive) while both genes were absent in 55 out of 59 strains (clones 1, 3 and 10; 16/59 were invasive and they did not harbour esp or hyl gene). The presence of either of the two genes in five major clones was not associated with invasiveness when invasive isolates were compared with non-invasive isolates $(p=0.88)$.

The Chi-square test revealed that esp and hyl could not be found more frequently in members of five predominant clones (38/97) than in single strains $(19 / 35)$ of $E$. faecium $(p=0.18)$. 


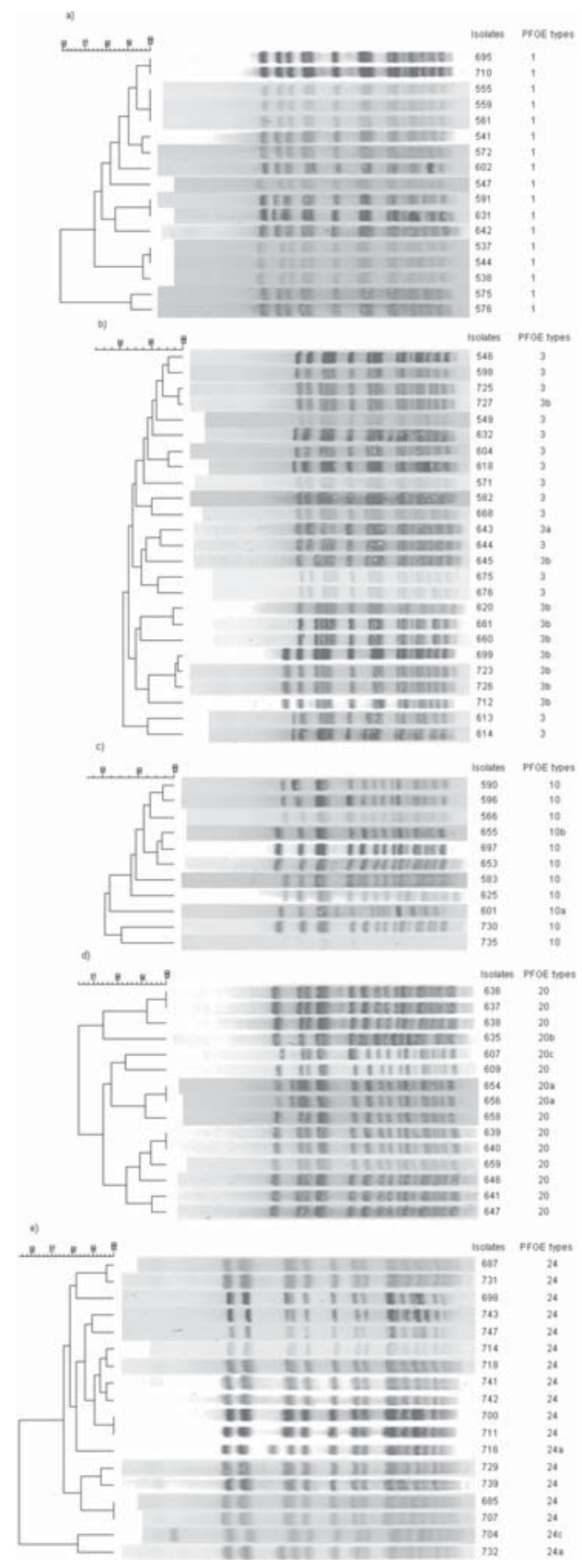

Figure 1. Dendrograms of 5 major clones of $E$. faecium showing similarity index among representative isolates: a) PFGE type 1; b) PFGE type 3; c) PFGE type 10; d) PFGE type 20; e) PFGE type 24 
Table III. Characteristics of eight major epidemic clones

\begin{tabular}{lllll}
\hline $\begin{array}{l}\text { PFGE type } \\
\text { (No of subtypes) }\end{array}$ & $\begin{array}{l}\text { No of isolates } \\
\text { (\% of the whole } \\
\text { collection) }\end{array}$ & $\begin{array}{l}\text { No of hospitals; } \\
\text { clinics of CCS }\end{array}$ & Years of isolation & $\begin{array}{l}\text { \% from isolation } \\
\text { source* }\end{array}$ \\
\hline $1(0)$ & $17(8.76)$ & $3 ; ;^{\mathrm{a}, \mathrm{b}, \mathrm{c}, \mathrm{d}}$ & $2004-2006$ & $2,4,11$ \\
$3(2)$ & $28(14.43)$ & $4 ; ;^{\mathrm{a}, \mathrm{b}, \mathrm{c}, \mathrm{d}, \mathrm{e}}$ & 2005,2006 & $14,4,10$ \\
$10(2)$ & $14(7.22)$ & $2 ; ;^{\mathrm{b}, \mathrm{d}}$ & 2005,2006 & $0,2,12$ \\
$20(3)$ & $20(10.31)$ & $1 ; ;^{\mathrm{a}, \mathrm{b}, \mathrm{c}}$ & 2005 & $1,5,14$ \\
$24(3)$ & $18(9.28)$ & $1 ; ;^{\mathrm{a}, \mathrm{b}, \mathrm{c}, \mathrm{d}, \mathrm{e}, \mathrm{f}}$ & 2006 & $8,3,7$ \\
$\mathrm{c}(0)$ & $12(6.19)$ & $1 ;{ }^{\mathrm{d}}$ & 2005,2006 & $12,0,0$ \\
$\mathrm{R}(1)$ & $10(5.16)$ & $1 ; ;^{\mathrm{a}, \mathrm{c}, \mathrm{g}}$ & 2005,2006 & $6,0,4$ \\
$\mathrm{G}(5)$ & $9(4.64)$ & $1 ; \mathrm{c}, \mathrm{d}$ & 2005,2006 & $9,0,0$ \\
\hline
\end{tabular}

Clinics of Clinical Center of Serbia (CCS): ${ }^{a}$ Clinic for Infectious and Tropical Diseases,

${ }^{\mathrm{b}} \mathrm{Clinic}$ for Hematology, ${ }^{\mathrm{c}}$ Intensive Care Unit of Urgent Center, ${ }^{\mathrm{d}} \mathrm{Clinic}$ for Pulmonary Diseases and Tuberculosis, ${ }^{\mathrm{e}} \mathrm{Clinic}$ for Neurosurgery, ${ }^{\mathrm{f}}$ Neurology Clinic, ${ }^{\mathrm{g}} \mathrm{Clinic}$ for Gynecology and Obstetrics * Order: invasive, non-invasive, carriage. Invasive: blood; non-invasive: wounds and urine; carrier: stool, sputum, vagina, skin, nose and pharyngeal swabs.

The majority of pathogenicity factor genes could be found in E. faecalis, except for the hyl gene, confined to E. faecium, while none of them were detected in E. raffinosus or E. gallinarum (Table IV).

\section{Discussion}

This research was conducted from 2002, when the first VRE in Serbia was identified, to October 2006. Before 2004, only two VRE had been isolated in the Bacteriology laboratory of the Clinic for Infectious and Tropical Diseases at the CCS; the increasing number of these bacteria from our hospitals after that period is consistent with the finding of increasing isolation of VRE in Europe [12], and the introduction of a screening technique for VRE of carrier origin. The greatest number of VRE originated from the CCS, which is the teaching hospital and where seriously ill patients from all over Serbia and the surrounding states of ex-Yugoslavia are sent for treatment. Four species of enterococci were identified in the CCS, while only E. faecium was found at the other health care institutions. PFGE results showed different clonal distributions of 5 major clones of E. faecium: while type 1, 3 and 10 spread over 3,4 and 2 hospitals, respectively, types 20 and 24 were found at the CCS only. The first three clones (in total 59/194 VRE) lacked both the esp and hyl genes (with exception of 4 strains), while the 
Table IV. Type specificity, pathogenicity factor content and capability of hemolyzis on blood agar for four species of VRE

\begin{tabular}{|c|c|c|c|c|c|c|c|c|c|c|c|}
\hline Type & esp & gel E & $c y l B$ & $c p d$ & $c o b$ & ace & efaAfs/efaAfm & cylA & asal & $h y l$ & hemol \\
\hline 1 (17) & - & - & $\begin{array}{ll}- \\
-\end{array}$ & - & - & - & + & - & - & - & - \\
\hline $2(2)$ & - & - & - & - & - & - & + & - & - & - & - \\
\hline 3 (15) & - & - & - & - & - & - & + & - & - & - & - \\
\hline 3a (3) & - & - & - & - & - & - & + & - & - & - & - \\
\hline $3 \mathbf{b}(10)$ & - & - & - & - & - & - & + & - & - & - & - \\
\hline $4(6)$ & - & - & - & - & - & - & + & - & - & + & - \\
\hline 4a (1) & - & - & - & - & - & - & + & - & - & + & - \\
\hline $5(1)$ & - & - & - & - & - & - & + & - & - & - & - \\
\hline $6(1)$ & - & - & - & - & - & - & + & - & - & - & - \\
\hline 7 (1) & + & - & - & - & - & - & + & - & - & + & - \\
\hline $8(1)$ & - & - & - & - & - & - & + & - & - & - & - \\
\hline 9 (3) & + & - & - & - & - & - & - & - & - & - & - \\
\hline $10(10)$ & - & - & - & - & - & - & + & - & - & - & - \\
\hline 10a (3) & - & - & - & - & - & - & + & - & - & + & - \\
\hline $10 \mathrm{~b}(1)$ & + & - & - & - & - & - & + & - & - & - & - \\
\hline $11(1)$ & - & - & - & - & - & - & + & - & - & - & - \\
\hline $12(1)$ & + & - & - & - & - & - & + & - & - & - & - \\
\hline $13(1)$ & - & - & - & - & - & - & + & - & - & + & - \\
\hline $14(1)$ & + & - & - & - & - & - & + & - & - & - & - \\
\hline $15(1)$ & + & - & - & - & - & - & + & - & - & + & - \\
\hline $16(1)$ & + & - & - & - & - & - & + & - & - & - & - \\
\hline 17 (2) & + & - & - & - & - & - & + & - & - & + & - \\
\hline $18(1)$ & - & - & - & - & - & - & + & - & - & - & - \\
\hline $19(2)$ & + & - & - & - & - & - & + & - & - & - & - \\
\hline 19a (1) & + & - & - & - & - & - & + & - & - & - & - \\
\hline $20(14)$ & + & - & - & - & - & - & + & - & - & - & - \\
\hline 20a (3) & + & - & - & - & - & - & + & - & - & - & - \\
\hline $20 \mathrm{~b}(1)$ & + & - & - & - & - & - & + & - & - & - & - \\
\hline $20 \mathrm{c}(2)$ & + & - & - & - & - & - & + & - & - & - & - \\
\hline $21(1)$ & - & - & - & - & - & - & + & - & - & - & - \\
\hline $22(1)$ & - & - & - & - & - & - & + & - & - & - & - \\
\hline $23(1)$ & - & - & - & - & - & - & + & - & - & + & - \\
\hline 24 (13) & - & - & - & - & - & - & + & - & - & + & - \\
\hline 24a (3) & - & - & - & - & - & - & + & - & - & + & - \\
\hline $24 c(1)$ & - & - & - & - & - & - & + & - & - & + & - \\
\hline $24 d(1)$ & - & - & - & - & - & - & + & - & - & + & - \\
\hline 25 (3) & + & - & - & - & - & - & + & - & - & + & - \\
\hline $26(1)$ & - & - & - & - & - & - & + & - & - & + & - \\
\hline 27 (1) & - & - & - & - & - & - & + & - & - & - & - \\
\hline $28(1)$ & + & - & - & - & - & - & + & - & - & - & - \\
\hline 29 (1) & - & - & - & - & - & - & + & - & - & + & - \\
\hline $30(1)$ & + & - & - & - & - & - & + & - & - & - & - \\
\hline 31 (1) & + & - & - & - & - & - & + & - & - & + & - \\
\hline $32(1)$ & - & - & - & - & - & - & + & - & - & - & - \\
\hline $33(1)$ & + & - & - & - & - & - & + & - & - & - & - \\
\hline 34 (1) & + & - & - & - & - & - & + & - & - & - & - \\
\hline 35 (1) & - & - & - & - & - & - & + & - & - & - & - \\
\hline $36(1)$ & + & - & - & - & - & - & + & - & - & - & - \\
\hline 37 (1) & + & - & - & - & - & - & + & - & - & - & - \\
\hline $38(1)$ & - & - & - & - & - & - & + & - & - & - & - \\
\hline 39 (1) & - & - & - & - & - & - & + & - & - & - & - \\
\hline 40 (1) & + & - & - & - & - & - & + & - & - & - & - \\
\hline 41 (1) & - & - & - & - & - & - & + & - & - & + & - \\
\hline $42(1)$ & - & - & - & - & - & - & + & - & - & + & - \\
\hline $43(1)$ & - & - & - & - & - & - & + & - & - & - & - \\
\hline 44 (1) & - & - & - & - & - & - & + & - & - & - & - \\
\hline
\end{tabular}


Table IV. (cont.)

\begin{tabular}{lccccccccccc}
\hline Type & $e s p$ & $g e l$ E & $c y l B$ & $c p d$ & $c o b$ & $a c e$ & efaAfslefaAfm & $c y l A$ & asal & hyl & hemol \\
\hline $45(1)$ & - & - & - & - & - & - & + & - & - & - & - \\
47 (1) & - & - & - & - & - & - & + & - & - & + & - \\
49 (2) & - & - & - & - & - & - & + & - & - & - & - \\
b (1) & - & + & - & + & + & + & + & - & + & - & - \\
c (12) & + & + & - & + & + & + & + & - & + & - & - \\
d (1) & + & + & + & + & + & + & + & + & + & - & - \\
d1 (1) & + & + & + & + & + & + & + & + & + & - & - \\
d2 (1) & + & + & + & + & + & + & + & + & + & - & - \\
g1 (2) & - & + & + & + & + & + & + & - & + & - & + \\
h (1) & + & + & + & + & + & + & + & - & + & - & + \\
m (2) & - & + & - & + & - & + & + & - & + & - & - \\
R (1) & - & - & - & - & - & - & ND & - & - & - & - \\
R1 (1) & - & - & - & - & - & - & ND & - & - & - & - \\
R2 (2) & - & - & - & - & - & - & ND & - & - & - & - \\
R3 (4) & - & - & - & - & - & - & ND & - & - & - & - \\
R4 (1) & - & - & - & - & - & - & ND & - & - & - & - \\
R5 (1) & - & - & - & - & - & - & ND & - & - & - & - \\
G (8) & - & - & - & - & - & - & ND & - & - & - & - \\
G1 (1) & - & - & - & - & - & - & ND & - & - & - & - \\
\hline
\end{tabular}

Numbers in parenthseis present number of isolates belonging to that clone (type and subtype) and are bolded. ND = not determined. E. faecium is marked with numbers, subrype with small letters added; E. faecalis is marked with small letters, subtypes have numbers added; E. raffinosus are marked with $\mathrm{R}$ and subtypes with numbers added; E. galinarum are marked with $\mathrm{G}$ and subtype with number added. Hemol $=$ hemolysis

other two (38/194 VRE) contained either the esp or hyl gene, known to be virulence elements of nosocomial enterococci that increase their ability to colonize hospitalized patients [13]. Finding esp or hyl genes in major clones typed as 20 and 24 indicate that the concentration of enterococcal pathogenicity factor genes in VRE is found in the CCS. As expected, our study could not however prove that invasive isolates of five major $E$. faecium clones contain more pathogenicity factor genes, esp and $h y l$, than non-invasive isolates $(p \geq 0.05)$. We also could not prove that the enterococcal surface protein gene (esp) is an important marker in epidemic strains, even though it is assumed that its presence seems to be limited to hospital-acquired E. faecium clones [14]. There was no statistical significance in the presence of the esp or hyl genes in members of predominant clones compared to single pulsotypes of $E$ faecium.

The finding that $9.8 \%$ enterococci was not one of the two most frequently encountered enterococcus species is somewhat different from previous studies where such species accounted for less than 5\% of VRE [1]. A high proportion of E. raffinosus and E. gallinarum in our study is apparently due to their clonal spread in the special conditions at the Intensive Care Unit of the Emergency Center, which seem to have changed the percentage of enterococcus species in a way which rarely occurs. Although the virulence of those species is low and they 
usually colonize the digestive tract of patients hospitalized in intensive care units, their capability of causing invasive infections has been previously recognized [15]. Vancomycin resistant E. gallinarum is known to carry the van $C$ gene which is located in a bacterial chromosome [1]. The gene cannot be transferred to other enterococci or other bacterial genera and is of little epidemiological relevance meaning that we chose not to investigate its presence in this species. On the contrary, VanA type of resistance is considered infectious, since the vanA gene is confined to mobile genetic elements which can easily be spread to other enterococci of the same or different species, or other genera, like $S$. aureus. In E. raffinosus and E. gallinarum from our study, the vanA gene probably was connected to their clinical (invasiveness) as well as epidemiological relevance (clonal spread). The vanA gene, carried on transposon or plazmid, could also be gained by $E$. faecalis clone c and two clones of E. faecium, which were also detected in strains originating from patients in the Intensive Care Unit of the Emergency Center.

Ampicillin has proven to be the drug of choice for E. faecalis in our study, and also effective for E. gallinarum [16]. To achieve the bactericidal effect, in severe enterococcal diseases, combined therapy with penicillin and aminoglycoside antibiotics is recommended. Even strains with lower levels of ampicillin resistance (MICs $\leq 64 \mu \mathrm{g} / \mathrm{ml}$ ) may still respond to a combination of therapy with ampicillin and an aminoglycoside, as long as the isolate does not demonstrate high-level resistance to the aminoglycoside co-drug [16]. In consideration with this, aminoglycoside therapy for all non-E. faecium from our study could be combined with ampicillin, for strains sensitive to high level dozes of gentamicin or streptomycin. Unfortunately, the percentage of high level gentamicin resistant (HLG) enterococci was high: $79.8 \%$ and $100 \%$ for E. faecium and E. faecalis respectively, compared to overall HLG resistance in Europe of $39.3 \%$ and $32.9 \%$ for E. faecium and E. faecalis, respectively [17]. The data provided by EARSS, though, refers to all vancomycin sensitive and resistant enterococci, while in this study only VRE were tested. Still, our HLG resistance rates, especially for E. faecalis are much bigger compared to those obtained by EARSS, when we take into account that the aminoglycoside resistance rate in VRE is two times higher than in vancomycin sensitive enterococci [18].

In conclusion, we have found genetically related clusters of strains from different hospitals, clusters that appeared in single institutions within the CCS, and strains of unique pulsotypes. The VRE in the present study were highly resistant to vancomycin, penicillins and ciprofloxacin, while their resistance to aminoglycisodes is cause for concern. Stringent epidemiological measures to stop clonal spreading of VRE within the CCS are warranted, as well as restricted use of broadspectrum antibiotics. 


\section{Acknowledgement}

Financial support: This paper was supported by UNESCO-ASM Travel Award for 2006 for M.J.

\section{Conflict of Interest}

None. The authors have no conflict of interest.

\section{References}

1. Cetinkaya, Y., Falk, P., Mayhall, C.G.: Vancomycin-resistant enterococci. Clin Microbiol Rev 13, 686-707 (2000).

2. Hegstad, K., Mikalsen, T., Coque, T.M., Werner, G., Sundsfjord, A.: Mobile genetic elements and their contribution to the emergence of antimicrobial resistant Enterococcus faecalis and Enterococcus faecium. Clin Microbiol Infect 16, 541-554 (2010).

3. Courvalin, P.: Genetics of glycopeptide resistance in gram-positive pathogens. Int J Med Microbiol 294, 479-486 (2005).

4. Werner, G., Coque, T.M., Hammerum, A.M., Hope, R., Hryniewicz, W., Johnson, A., Klare, I., Kristinsson, K.G., Leclercq, R., Lester, C.H., Lillie, M., Novais, C., OlssonLiljequist, B., Peixe, L.V., Sadowy, E., Simonsen, G.S., Top, J., Vuopio-Varkila, J., Willems, R.J., Witte, W., Woodford, N.: Emergence and spread of vancomycin resistance among enterococci in Europe. Eurosurveillance 13, 19046 (2008). Available online: http:// www.eurosurveillance.org/ViewArticle.aspx?ArticleId=19046

5. Facklam, R.R., Sahm, D.F., Teixeira, L.M.: Enterococcus. In Murray, P. (ed.), Manual of clinical microbiology. ASM Press, Washington, D.C., 1999, pp. 297-305.

6. Clinical and Laboratory Standards Institute (2007): Performance standards for antimicrobial susceptibility testing; Seventeenth Informational Supplement M100-S16. Clinical and Laboratory Standards Institute, Wayne, PA, USA.

7. Donabedian, S., Chow, J.W., Shlaes, D.M., Green, M., Zervos, M.J.: DNA probes and contour-clamped homogenous field electrophoresis for identification of enterococci to the species level. J Clin Microbiol 33, 141-145 (1995).

8. Tenover, F.C., Arbeit, R.D., Goering, R.V., Mickelsen, P.A., Murray, B.E., Persing, D.H., Swaminathan, B.: Interpreting chromosomal DNA restriction patterns produced by pulsed-field gel electrophoresis: criteria for bacterial strain typing. J Clin Microbiol 33, 2233-2239 (1995).

9. Dutka-Malen, S., Evers, S., Courvalin, P.: Detection of glycopeptide resistance genotypes and identification to the species level of clinically relevant enterococci by PCR. J Clin Microbiol 32, 24-27 (1995).

10. Eaton T.J., Gasson, M.J.: Molecular screening of enterococcus virulence determinants and potential for genetic exchange between food and medical isolates. Appl Env Microbiol 67, 1628-1635 (2001). 
11. Vankerckhoven, V., Van Autgaerden, T., Vael, C., Chapelle, S., Rossi, R., Jabes, D., Goosens, H.: Development of a multiplex PCR for the detection of asal, gel e, cyl A, esp, and $h y l$ genes in Enterococci and survey for virulence determinants among European hospital isolates of Enterococcus faecium. J Clin Microbiol 42, 4473-4479 (2004).

12. Deshpande, L.M., Fritsche, T.R., Moet, G.J., Biedenbach, D.J., Jones, R.N.: Antimicrobial resistance and molecular epidemiology of vancomycin-resistant enterococci from North America and Europe: a report from the SENTRY antimicrobial surveillance program. Diagn Microbiol Infect Dis 58, 163-170 (2007).

13. Hällgren, A., Claesson, C., Saeedi, B., Monstein, H.J., Hanberger, H., Nilsson, L.E.: Molecular detection of aggregation substance, enterococcal surface protein, and cytolysin genes and in vitro adhesion to urinary catheters of Enterococcus faecalis and E. faecium of clinical origin. Int J Med Microbiol 299, 323-332 (2009).

14. Willems, R.J., Homan, W., Top, J., van Santen-Verheuvel, M., Tribe, D., Manzioros, X., Gaillard, C., Vandenbroucke-Grauls, C.M., Mascini, E.M., other authors.: Variant esp gene as a marker of a distinct genetic lineage of vancomycin-resistant Enterococcus faecium spreading in hospitals. Lancet 357, 853-855 (2001).

15. Ruiz-Garbajosa, P., Cantón, R., Pintado, V., Coque, T.M., Willems, R., Baquero, F., del Campo, R.: Genetic and phenotypic differences among Enterococcus faecalis clones from intestinal colonisation and invasive disease. Clin Microbiol Infect 12, 1193-1198 (2006).

16. Murray, B.E.: Vancomycin-resistant enterococcal infections. N Engl J Med 342, 710-721 (2000).

17. The European Antimicrobial Resistance Surveillance System. EARSS Results. [Database on the internet.] http://www.ecdc.europa.eu/en/ activities/surveillance/EARS-Net/Pages/ Database.aspx. doi:10.2900/93403

18. Yazgi, H., Ertek, M., Erol, S., Ayyildiz, A.: A comparison of high-level aminoglycoside resistance in vancomycin-sensitive and vancomycin-resistant Enterococcus species. J Int Med Res 30, 529-534 (2002). 